\title{
Doctors' Knowledge and Practices Regarding Chronic Kidney Disease at a Tertiary Care Hospital
}

\author{
Mahvesh Mahmud ${ }^{1}$, Nida Hussain ${ }^{1}$, Amal Kamal ${ }^{1}$, \\ Zarak Iqbal Samoo ${ }^{2}$, Wahaaj Ali Khan ${ }^{2}$
}

\section{Abstract}

Background: The complications of chronic kidney disease (CKD) significantly contribute to morbidity and mortality, therefore clinical practice guidelines have been developed to facilitate early detection and treatment. However, given the high prevalence of CKD, many patients with early CKD are seen by non-nephrologists, who need to be aware of CKD complications, screening methods and treatments goals in order to initiate timely therapy and referral.

Methods: This was a cross-sectional study conducted at three campuses of the Ziauddin University Hospital, Karachi, Pakistan in 2016. A questionnaire based survey was conducted to assess the knowledge and practices of doctors from various specialties regarding CKD.

Results: We performed a questionnaire based survey to assess knowledge and practice patterns in CKD care among 156 doctors. There were 63 male and 50 female respondents. There were 24 attending doctors, 73 post-graduate trainees and 25 house-officers. Our data showed that although CKD risk factors are generally recognized, there is a paucity of knowledge regarding CKD management guidelines and staging of CKD. There is an awareness regarding timely referral to nephrology, but many would still not refer at the appropriate stage. Many also do not use standard equations to calculate Glomerular Filtration rate (GFR) and Creatinine Clearance]. Most do screen for diabetic nephropathy, know about ACE-I/ARBs and provide dietary counseling to CKD patients. The majority do not read medical journals to keep their knowledge up-to-date. Junior doctors (post-graduate trainees and house-officers) fared better than attending doctors in the knowledge and practice parameters.
1 Department of Medicine, Ziauddin University Hospital, Clifton Campus 4/B, Sharah-e-Ghalib, Block 6, Clifton Karachi, Pakistan.

2 Ziauddin University, Clifton Campus 4/B, Sharah-e-Ghalib, Block 6, Clifton Karachi, Pakistan.

Contact information:

Mahvesh Mahmud.

झ" mahveshmahmud@gmail.com 
Conclusion: Our survey shows that there is a requirement for continuing education and awareness among doctors regarding CKD and its management guidelines, as well as timely referral to a nephrologist. Facing a growing CKD incidence, doctors can have an impact on preventing its progression and associated complications with increased familiarity of local guidelines.

\section{Keywords}

Chronic Kidney Disease;

Doctors, Knowledge; Practices; practice guidelines.

\section{Introduction}

Chronic kidney disease (CKD) is a common and growing problem worldwide. It is in fact, a worldwide epidemic health problem of increasing prevalence and expenditure [1]. It is a major health problem globally, casting an enormous burden on healthcare systems, is a source of psychological distress, and is associated with cardiovascular diseases, resulting in substantial morbidity and mortality [2]. According to the Global Burden of Disease Study, CKD was ranked $18^{\text {th }}$ in the list of causes of total number of global deaths in 2010 [3]. Approximately $12.5 \%$ of adults in Pakistan show some evidence of kidney damage and/or reduced kidney function [4]. Identification of CKD requires recognition of individual risk and appropriate laboratory testing [serum creatinine and/or urinary protein] [5], since symptoms generally do not manifest in the earlier stages of CKD.

The worldwide rise in the prevalence of CKD demands changes in the global approach towards the prevention of CKD, mainly by detecting the risk factors [6]. Hypertension and diabetes mellitus are the leading important risk factors for CKD in developing countries [7]. Many studies have confirmed this association - these two diseases share risk factors such as smoking and obesity, and promote vascular alterations that increase the risk for developing kidney impairment [8]. With the aging of the population and the increasing incidence of obesity, hypertension and diabetes, the number of individuals at risk for CKD will continue to increase [9]. In 2003, the
American Heart Association released a statement that CKD is a major risk factor for coronary disease $[10,11]$. Two later studies demonstrated that the risk of death and cardiovascular events in people with coronary artery disease are directly related to the degree of renal dysfunction $[12,13]$. The high prevalence of CKD in the population in Pakistan is not unexpected since the incidence of hypertension and diabetes in Pakistan is one of the highest in the world [14, 15].

Earlier-stage CKD can also lead to several complications, such as anemia and bone mineral metabolism disorders, as well as poor outcomes, including cardiovascular events, morbidity, and mortality [16], in addition to progression to end-stage renal disease (ESRD), requiring dialysis or transplant for survival. Despite these known adverse consequences of CKD, the majority of persons with the disease, especially prior to ESRD, remain unaware of their disease [17-19]. Awareness of CKD remains unacceptably low, despite recent attempts to increase awareness through dissemination of clinical practice guidelines and recommendations for patients with CKD or its risk factors to providers [20-22], including community awareness events such as World Kidney Day $[23,24]$. Earlier recognition of CKD can slow the progression of CKD, prevent complications, and reduce cardiovascular-related outcomes; additionally, early referral to a nephrologist has been shown to improve outcomes for those who progress to end-stage renal disease [27-30]. It has been observed that physicians other than nephrologists are less 
likely to recognize CKD and differ in their clinical evaluation of CKD [31]. In a significant number of cases, CKD patients are referred to nephrologists much later than it would deem appropriate [32]. Late evaluation of CKD patients by nephrologists, especially those presenting in Stage 5 CKD, is associated with suboptimal pre-dialysis care and increased mortality [33-35]. This is especially pertinent to developing countries, where support for renal replacement therapy is constrained for the vast majority of ESRD patients by cost and lack of technological advancements [36].

Recent studies across Pakistan have shown a general lack of awareness among doctors regarding chronic kidney disease. One study from Lahore showed that the majority of doctors have poor to average knowledge about kidney disease; most think that nephrology services are inadequate in their hospitals and the subject must be taught before graduation from medical school [37]. A study from Karachi identified specific gaps in the knowledge and approach of general practitioners (GPs) regarding the diagnosis and management of CKD... it highlighted the need for educational efforts to increase awareness of clinical practice guidelines and recommendations for patients with CKD, in order to improve management and clinical outcomes of this population of patients [38]. Another study from Islamabad showed a need for continuing education and awareness among physicians regarding CKD management, and the benefits of timely referral to a nephrologist [31]. According to a 2006 study, there were only about 80 formally trained nephrologists in Pakistan for a population of about 160 million (while the USA had more than 5000 nephrologists for a population of 300 million) [39], and the situation is not much different ten years later. Until the public health services in Pakistan are developed further and the referral system to nephrologists is improved, doctors other than nephrologists will continue to see and manage patients with CKD, and it is imperative that they should be aware of the guidelines regarding the detection, monitoring and treatment of CKD.

A Knowledge, Attitude and Practices (KAP) survey is a quantitative method [predefined questions formatted in standardized questionnaires] that provides access to quantitative and qualitative information. KAP surveys reveal misconceptions or misunderstandings that may represent obstacles to the activities that we would like to implement and potential barriers to behavior change [40]. In certain situations, extensive training provides ample information, but there is still no implementation due to a lack of conviction about the importance of the subject or the belief that this information pertains to a different population and cannot be practiced in this setting. We therefore aimed to implement a "Knowledge and Practice" study for chronic kidney disease to identify areas for improvement, in order to develop an intervention strategy that reflects specific local circumstances and the cultural factors that influence them; and to plan educational and training activities that are suited to the respective population involved.

\section{Materials and Methods}

We conducted a cross-sectional study of doctors to assess their awareness and approach towards CKD diagnosis and management at the three campuses of the Ziauddin Hospital, Karachi (a tertiary care hospital) from Jan-Mar 2016.

\section{Survey instrument}

We reviewed the Kidney Disease Outcomes and Quality Initiatives (KDOQI) commentary on the 2012 KDIGO clinical practice guidelines for the evaluation and management of CKD [22] and identified themes relevant to doctors providing pre-dialysis CKD care and referring patients to nephrologists. In the absence of a validated questionnaire to meet the objectives of our study, we designed a questionnaire to meet local needs. The level of difficulty of 
the questions was appropriate for doctors who had completed their "house-job", regardless of which clinical sub-specialty they were now pursuing. The "house-job" in Pakistan is one year of mandatory clinical training after graduation from medical school in Pakistan, in which the "house-officers" [HOs] rotate through the Departments of Medicine and Surgery and gain comprehensive clinical experience. The post graduate training is a four year long training in different specialties after completion of the house-job. The survey instrument was piloted and modified based on feedback. The questionnaire was anonymous with no demands for personal information. Doctors' participation was voluntary after informed consent

Data was collected on a structured questionnaire containing questions on the following basic themes:

- Academic position: data was collected on the academic position of the doctors, as well as information on the number of years they had been in practice. For post-graduate trainees (PGs), the year of training was ascertained.

- Knowledge of CKD, including use of formulae for estimated (EGFR) to stage CKD, awareness of the stages of CKD and of the National Kidney Foundation (NKF) KDOQI guidelines for managing CKD, knowledge of "age-related decline in GFR", risk factors for, and complications of CKD. It also included questions on timing of referral to nephrologists, measurement of urine protein in CKD evaluation, monitoring of anemia and bone-mineral parameters in patients with CKD.

- Practice questions including routine calculation of eGFR for CKD evaluation, dosing of medications according to creatinine clearance, screening for diabetic kidney disease, management of hypertension in CKD including blood pressure goals, provision of dietary counseling to patients with CKD, the need for more education on the subject, and sources of information about CKD.

\section{Data Collection Methodology}

The subjects were asked to fill out the questionnaires at their workplace in front of the authors conducting the survey, and the filled forms were returned within ten to twenty minutes. A repeat visit was conducted after two days to include those subjects who could not be contacted during the first visit. Overall, 122 doctors out of the 196 enlisted could be surveyed.

\section{Study Participants}

The sample size was estimated to be 96 and convenience sampling was the method employed. The questionnaires were distributed to doctors from the Departments of Medicine, Family Medicine, Gynaecology, Dermatology, Psychiatry, Surgery, Ophthalmology and Otolaryngology, as these specialties are the referral base to the nephrologists at the hospital.

\section{Inclusion/Exclusion Criteria}

We excluded doctors who had not yet started their house-job.

\section{Statistical analysis}

All statistical analyses were conducted using the Statistical package for social science SPSS version 21. A descriptive analysis was carried out for demographic characteristics and results, and presented as mean \pm standard deviation. Frequencies and percentages were calculated for gender, position of work, and postgraduate qualifications. The data were sub-analyzed using the Chi square test for differences in knowledge among doctors according to their year of training, their academic positions and specialties.

\section{Results}

The questionnaires were distributed to 156 doctors (keeping in mind wastage and non-response), out of which 122 completed the survey. There were 63 male and 59 female respondents. There were 24 
Figure 1: Academic positions of attending doctors (Consultants refers to attending doctors who do not have faculty positions, senior registrars are attending doctors who have just completed their postgraduate degree. Assistant professors, associate professors and professors are higher up in the academic hierarchy in that order). AssocProf: Associate Professor.

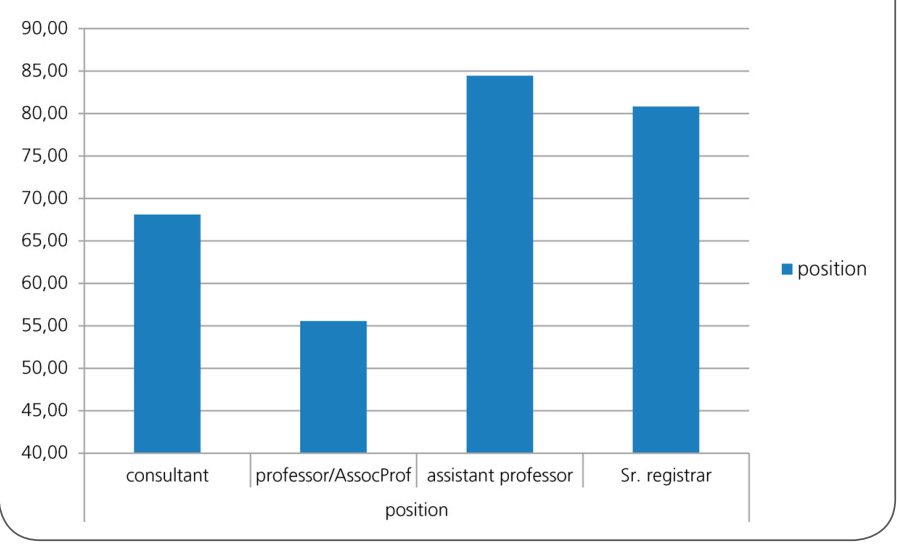

attending doctors, 25 house-officers and 73 were post-graduate trainees. Figure 1 shows the academic positions of the consultants who took part in the survey.

Figure 2 shows the subspecialty break-up for the respondents, figure 3 shows the number of years all the doctors had been in practice, and Table 1 enlists the year of training for the post-graduate trainees.

Table 2 is a detailed break-up of the knowledge parameters in the questionnaire. The majority of res-
Figure 2: Sub-specialties of the respondents.

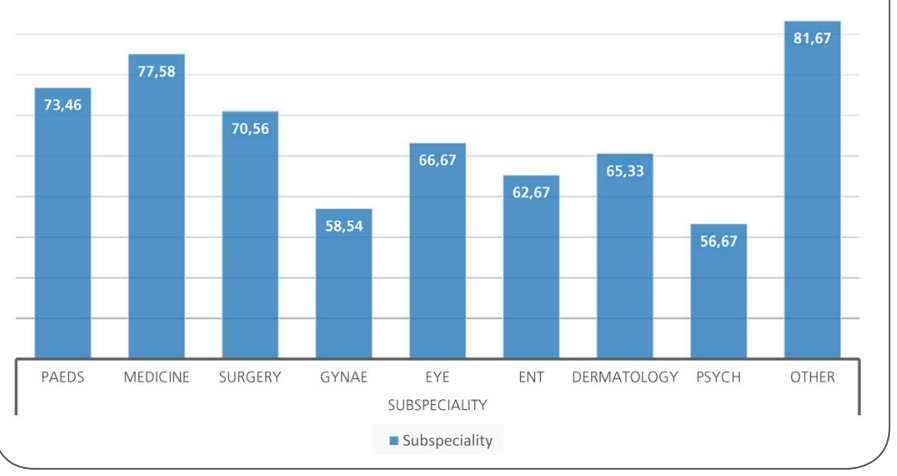

Figure 3: Years of practice 1: 0-5 years, 2: 5-10 years, 3: 10-20 years, 4: $>20$ years.

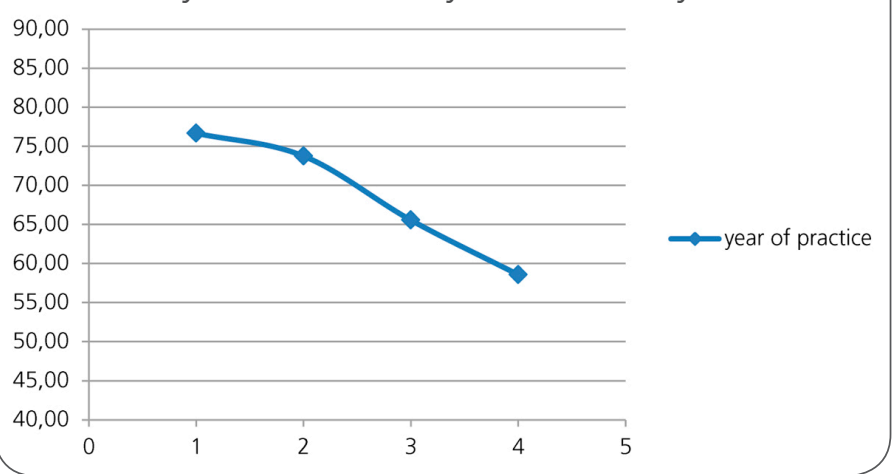

Table 1. Year of training of post-graduate trainees

\begin{tabular}{|c|c|}
\hline Years & $\mathrm{n}=73$ \\
\hline 1 & 20 \\
\hline 2 & 33 \\
\hline 3 & 9 \\
\hline 4 & 11 \\
\hline
\end{tabular}

Table 2. Knowledge parameters by position.

\begin{tabular}{|c|c|c|c|c|c|c|}
\hline \multirow{3}{*}{ Questions } & \multicolumn{2}{|c|}{ House-Officer } & \multicolumn{2}{|c|}{ Post-graduate trainee } & \multicolumn{2}{|c|}{ Attending Doctor } \\
\hline & $\mathrm{N}$ & & $\mathrm{N}$ & & N & \\
\hline & 25 & $\%$ & 73 & $\%$ & 24 & $\%$ \\
\hline What is the best way to stage CKD? (eGFR) & 18 & 72.0 & 62 & 84.9 & 15 & 62.5 \\
\hline How many stages of CKD are you aware of? & 10 & 40.0 & 52 & 71.2 & 11 & 45.8 \\
\hline $\begin{array}{l}\text { Are you aware of standard guidelines for CKD } \\
\text { management? }\end{array}$ & 0 & 0.0 & 18 & 24.7 & 9 & 37.5 \\
\hline $\begin{array}{l}\text { Which is the most commonly used formula for GFR } \\
\text { estimation for staging CKD? }\end{array}$ & 2 & 8.0 & 10 & 13.7 & 5 & 20.8 \\
\hline Are you aware of age-related decline in GFR? & 20 & 80 & 51 & 69.9 & 19 & 79.2 \\
\hline
\end{tabular}




\section{Questions}

\begin{tabular}{|c|c|c|c|c|c|}
\hline \multicolumn{2}{|c|}{ House-Officer } & \multicolumn{2}{|c|}{ Post-graduate trainee } & \multicolumn{2}{|c|}{ Attending Doctor } \\
\hline $\mathrm{N}$ & & $\mathrm{N}$ & & $\mathrm{N}$ & \\
\hline 25 & $\%$ & 73 & $\%$ & 24 & $\%$ \\
\hline
\end{tabular}

Are you aware that the following are risk factors for CKD?

\begin{tabular}{|c|c|c|c|c|c|c|c|}
\hline \multicolumn{2}{|l|}{ Diabetes Mellitus } & 25 & 100.0 & 71 & 97.3 & 22 & 91.7 \\
\hline \multicolumn{2}{|l|}{ Hypertension } & 24 & 96.0 & 71 & 97.3 & 22 & 91.7 \\
\hline \multicolumn{2}{|l|}{ Renal stone disease } & 18 & 72.0 & 60 & 82.2 & 19 & 79.2 \\
\hline \multicolumn{2}{|l|}{ Chronic glomerulonephritis } & 23 & 92.0 & 66 & 90.4 & 24 & 100.0 \\
\hline \multirow{3}{*}{$\begin{array}{l}\text { Are you aware that the } \\
\text { following are complications } \\
\text { of CKD? }\end{array}$} & Anemia & 21 & 84.0 & 69 & 94.5 & 24 & 100 \\
\hline & Cardiovascular disease & 20 & 80.0 & 60 & 82.2 & 16 & 66.7 \\
\hline & Bone disease & 22 & 88.0 & 61 & 83.6 & 20 & 83.3 \\
\hline \multicolumn{2}{|c|}{$\begin{array}{l}\text { Does late referral to a nephrologist cause high morbidity } \\
\text { and mortality? }\end{array}$} & 21 & 84 & 71 & 97.3 & 21 & 87.5 \\
\hline \multicolumn{2}{|c|}{ What is the goal BP for CKD patients? } & 8 & 32 & 46 & 63 & 13 & 54.2 \\
\hline \multicolumn{2}{|c|}{$\begin{array}{l}\text { After how many years of diagnosis of DM Type } 2 \text { should } \\
\text { screening for DM start? }\end{array}$} & 13 & 52 & 39 & 53.4 & 16 & 66.7 \\
\hline
\end{tabular}

pondents identified eGFR as the best way of staging $C K D$. The majority of post-graduate $(P G)$ trainees were aware of the five stages of CKD, but this did not hold true for attending doctors and consultants. The majority of doctors were not aware of standard guidelines for CKD management, neither were they aware of the formula (MDRD) used for CKD staging. $A$ vast majority was aware of "age-related decline in GFR", and they could correctly identify diabetes mellitus (DM), hypertension, renal stone disease and chronic glomerulonephritis as risk factors for chronic kidney disease. A significant number correctly identified the complications of CKD. Most also knew that late referral to nephrologists increases mortality and morbidity among CKD patients. The goal BP for CKD was correctly identified by $63 \%$ of $P G s$ and $54 \%$ of attending doctors, but only $32 \%$ of houseofficers [HOs]. A majority of the respondents knew that screening for diabetic nephropathy should begin with the diagnosis of diabetes mellitus (DM).

Table 3 is a detailed break-up of the answers for the practice parameters of the questionnaire. A ma- jority of doctors did refer patients with CKD Stage 3 and below to nephrology, and they also routinely measured urine protein, and monitored anemia and bone markers in patients with CKD. However, it was the majority of the PG trainee group only who routinely use standard equations to calculate GFR in CKD patients, and also used creatinine clearance to adjust medication doses. The majority of doctors correctly identified ACE/ARBs as the anti-hypertensives of choice for CKD patients. An overwhelming number refer to textbooks for information/updates on CKD as compared to journals, seminars and online resources. The majority of doctors also provided dietary counselling to CKD patients and routinely measured urinary microalbumin to screen for diabetic nephropathy.

Table 4 is a post-hoc (Tukey) test comparing all the parameters between the attending doctors as per their position. The senior registrars and assistant professors had more correct answers [indicating superior knowledge/practice] as compared with associate professors, professors and consultants. 
Table 3. Practice parameters for the respondents.

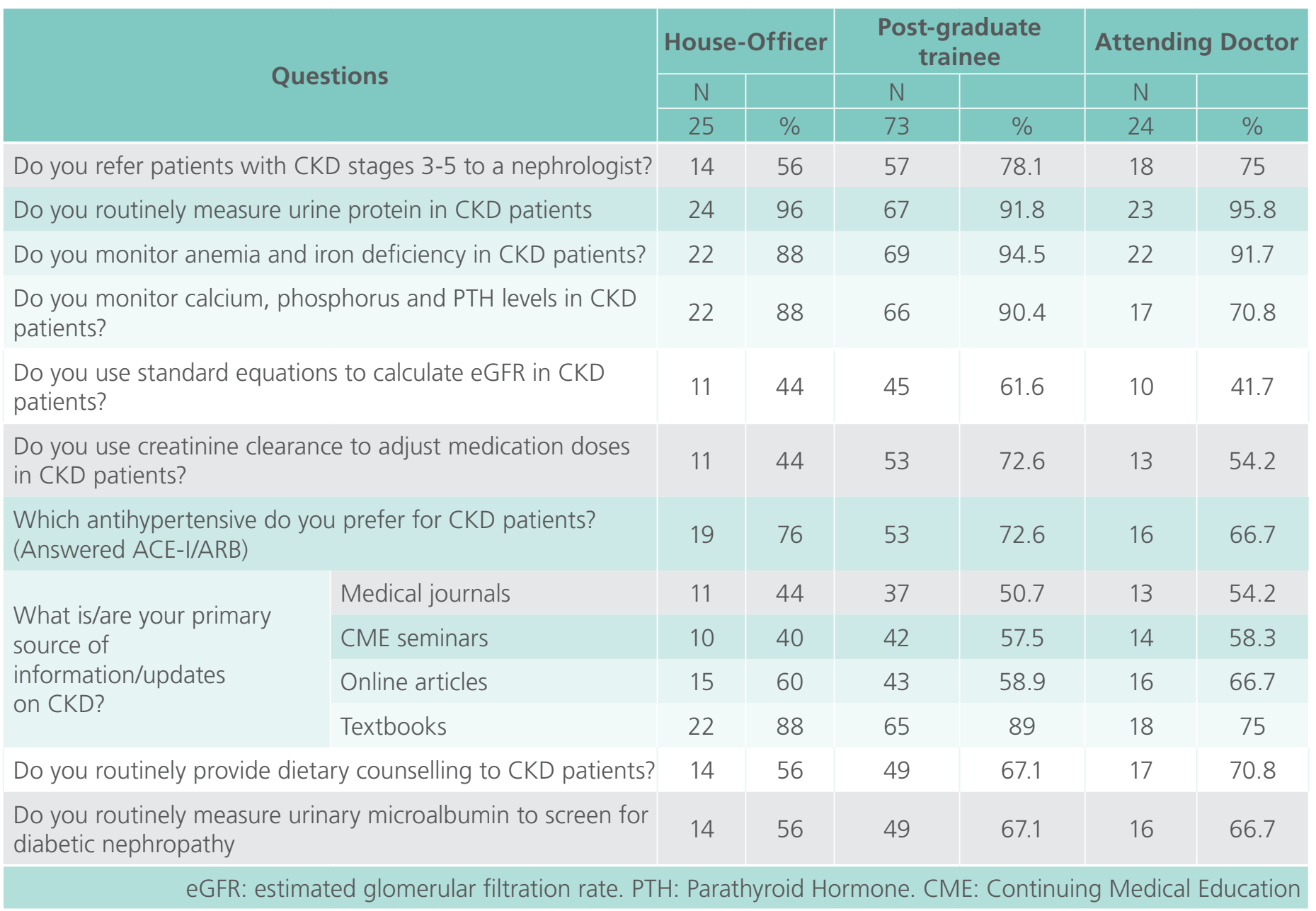

Table 4. Post-hoc (Tukey) test for comparison by position of the attending doctors. Tukey HSD-contrasts

\begin{tabular}{|c|c|c|c|c|c|c|}
\hline \multicolumn{7}{|c|}{ Multiple Comparisons } \\
\hline \multirow{2}{*}{ (I) position } & \multirow{2}{*}{ (J) position } & \multirow{2}{*}{$\begin{array}{c}\text { Mean } \\
\text { Difference (I-J) }\end{array}$} & \multirow{2}{*}{$\begin{array}{l}\text { Std. } \\
\text { Error }\end{array}$} & \multirow{2}{*}{ Sig. } & \multicolumn{2}{|c|}{ 95\% Confidence Interval } \\
\hline & & & & & Lower Bound & Upper Bound \\
\hline \multirow{3}{*}{ Consultant } & professor/AssocProf & 12.53968 & 7.14901 & .324 & -7.4699 & 32.5493 \\
\hline & assistant professor & -16.34921 & 8.86725 & .283 & -41.1681 & 8.4697 \\
\hline & Sr. registrar & -12.73810 & 6.65044 & .253 & -31.3522 & 5.8761 \\
\hline \multirow{3}{*}{$\begin{array}{l}\text { Professor/Assoc } \\
\text { Prof }\end{array}$} & consultant & -12.53968 & 7.14901 & .324 & -32.5493 & 7.4699 \\
\hline & assistant professor & $-28.88889 *$ & 9.08623 & .022 & -54.3207 & -3.4571 \\
\hline & Sr. registrar & $-25.27778^{*}$ & 6.93972 & .008 & -44.7016 & -5.8539 \\
\hline \multirow{3}{*}{$\begin{array}{l}\text { Assistant } \\
\text { Professor }\end{array}$} & consultant & 16.34921 & 8.86725 & .283 & -8.4697 & 41.1681 \\
\hline & professor/AssocProf & $28.88889 *$ & 9.08623 & .022 & 3.4571 & 54.3207 \\
\hline & Sr. registrar & 3.61111 & 8.69940 & .975 & -20.7380 & 27.9602 \\
\hline \multirow{3}{*}{ Sr. registrar } & consultant & 12.73810 & 6.65044 & .253 & -5.8761 & 31.3522 \\
\hline & professor/AssocProf & $25.27778^{*}$ & 6.93972 & .008 & 5.8539 & 44.7016 \\
\hline & assistant professor & -3.61111 & 8.69940 & .975 & -27.9602 & 20.7380 \\
\hline
\end{tabular}

Dependent Variable: perc. Tukey HSD. *: The mean difference is significant at the 0.05 level. 
Table $\mathbf{5}$ is a post-hoc (Tukey) test comparing all the parameters between all the doctors as per the number of years they had been in practice - with increasing number of years of practice, the CKD knowledge and practice parameters showed a significant decline.

Table 6 is the ANOVA test of regression between $\mathrm{HOs}$ and $\mathrm{PG}$ trainees, showing that PG trainees fa-

Table 5. Post-hoc (Tukey) test for comparison by years of practice of all doctors.

\begin{tabular}{|c|c|c|c|c|c|c|}
\hline \multicolumn{7}{|c|}{ Multiple Comparisons } \\
\hline \multirow{2}{*}{$\begin{array}{l}\text { (I) year of } \\
\text { practice }\end{array}$} & \multirow{2}{*}{$\begin{array}{l}\text { (J) year of } \\
\text { practice }\end{array}$} & \multirow{2}{*}{$\begin{array}{c}\text { Mean } \\
\text { Difference (I-J) }\end{array}$} & \multirow{2}{*}{ Std. Error } & \multirow{2}{*}{ Sig. } & \multicolumn{2}{|c|}{ 95\% Confidence Interval } \\
\hline & & & & & Lower Bound & Upper Bound \\
\hline \multirow{3}{*}{$0-5$ yrs } & $5-10$ yrs & 2.91667 & 5.24713 & .945 & -11.0187 & 16.8520 \\
\hline & $10-20$ yrs & 11.11111 & 8.07848 & .520 & -10.3438 & 32.5660 \\
\hline & more then 20 yrs & $18.09524^{*}$ & 5.54674 & .010 & 3.3642 & 32.8263 \\
\hline \multirow{3}{*}{$5-10$ yrs } & $0-5$ yrs & -2.91667 & 5.24713 & .945 & -16.8520 & 11.0187 \\
\hline & $10-20$ yrs & 8.19444 & 9.11070 & .805 & -16.0018 & 32.3907 \\
\hline & more then $20 \mathrm{yrs}$ & 15.17857 & 6.96486 & .143 & -3.3188 & 33.6759 \\
\hline \multirow{3}{*}{$10-20$ yrs } & $0-5$ yrs & -11.11111 & 8.07848 & .520 & -32.5660 & 10.3438 \\
\hline & $5-10$ yrs & -8.19444 & 9.11070 & .805 & -32.3907 & 16.0018 \\
\hline & more then $20 \mathrm{yrs}$ & 6.98413 & 9.28649 & .875 & -17.6790 & 31.6472 \\
\hline \multirow{3}{*}{$\begin{array}{l}\text { more than } 20 \\
\text { yrs }\end{array}$} & $0-5$ yrs & $-18.09524^{*}$ & 5.54674 & .010 & -32.8263 & -3.3642 \\
\hline & $5-10 \mathrm{yrs}$ & -15.17857 & 6.96486 & .143 & -33.6759 & 3.3188 \\
\hline & $10-20$ yrs & -6.98413 & 9.28649 & .875 & -31.6472 & 17.6790 \\
\hline
\end{tabular}

Dependent Variable: perc. Tukey HSD. *: The mean difference is significant at the 0.05 level.

Table 6. Regression HO/PG.

\begin{tabular}{|c|c|c|c|c|c|c|}
\hline \multicolumn{7}{|c|}{ ANOVA $^{a}$} \\
\hline & del & Sum of Squares & df & Mean Square & $\mathbf{F}$ & Sig. \\
\hline \multirow{3}{*}{1} & Regression & 1164.243 & 1 & 1164.243 & 7.332 & $.008^{b}$ \\
\hline & Residual & 15243.580 & 96 & 158.787 & & \\
\hline & Total & 16407.823 & 97 & & & \\
\hline
\end{tabular}

Table 7. Spearman's rho, a test for correlation.

\begin{tabular}{|c|c|c|c|c|c|}
\hline \multicolumn{6}{|c|}{ Correlations } \\
\hline & & & perc & $\begin{array}{l}\text { year of } \\
\text { practice }\end{array}$ & $\begin{array}{c}\text { year of } \\
\text { training in PG }\end{array}$ \\
\hline \multirow{9}{*}{ Spearman's rho } & \multirow{3}{*}{ percentage } & Correlation Coefficient & 1.000 & $-.377 * \star$ & $.310 * *$ \\
\hline & & Sig. (2-tailed) & & .005 & .008 \\
\hline & & $\mathrm{N}$ & 125 & 55 & 73 \\
\hline & \multirow{3}{*}{ year of practice } & Correlation Coefficient & $-.377 \star \star$ & 1.000 & . \\
\hline & & Sig. (2-tailed) & .005 & 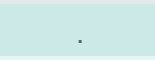 & . \\
\hline & & $\mathrm{N}$ & 55 & 55 & 22 \\
\hline & \multirow{3}{*}{$\begin{array}{l}\text { year of training } \\
\text { in } P G\end{array}$} & Correlation Coefficient & $.310 * \star$ & . & 1.000 \\
\hline & & Sig. (2-tailed) & .008 & & \\
\hline & & $\mathrm{N}$ & 73 & 22 & 73 \\
\hline
\end{tabular}


red better than their juniors in the knowledge and practice parameters for CKD management.

Table 7 details the Spearman's Rho, a test for ordinal variables, to see whether the mentioned variables are correlated. It checks if an ordinal variable (years of practice, years of PG training) is correlated with a continuous variable (percentage in this case). The $p$-values are significant and it shows that as the years of practice increased the percentage correct score decreased, while as the years of training as PGs increased, the percentage correct score increased within that sub-group.

\section{Discussion}

The results of our survey highlight the areas that need to be worked upon in order to improve the quality of care for patients with CKD. In Pakistan, patients suffering from CKD are mainly under care of internists and general practitioners until they reach advanced kidney failure when they are referred to a nephrologist [38]. The majority of doctors were aware of eGFR being the best way to stage kidney disease as compared to serum urea or creatinine levels. However, most attending doctors and house-officers were not aware that there are five stages of CKD, and only a small minority of all could correctly identify the MDRD equation used for eGFR estimation for CKD staging. Most were not aware of standard guidelines used for the management of CKD. Only $44 \%$ of HOs, $61.6 \%$ of PGs and $41.7 \%$ of attending doctors actually used standard equations to calculate eGFR in CKD patients, and 44\% of HOs, $72.6 \%$ of PGs, and $54.2 \%$ of attending doctors actually used the Creatinine Clearance to adjust medication doses in CKD patients.

Traditionally, physicians have been relying on measurement of serum creatinine alone for kidney disease detection and management. The KDOQI guidelines recommend that the serum creatinine alone is not an accurate index of the level of GFR and that the level of GFR should be estimated from prediction equations that take into account the serum creatinine concentration and some or all of the following variables: age, gender, race and body size [41]. Incorporation of these guidelines into clinical practice facilitates early detection of CKD by primary care providers, identification and management of its complications, and also promotes timely referral of patients to nephrology services [38]. A UNYNET study on ten primary care providers revealed that only one used eGFR, while the rest relied on blood urea, serum creatinine or urinalysis alone for diagnosing CKD [42]. In another study at a tertiary care hospital, $78 \%$ of the respondents were aware of eGFR being a better tool to assess kidney disease compared to the serum creatinine alone, but $48 \%$ either did not know when to refer based on eGFR, or still referred on the basis of serum creatinine alone [31]. However, a study on general practitioners (GPs) in Karachi showed that $78 \%$ of them would rely on serum creatinine for detection of kidney disease [38]. Evidence has shown that eGFR measurement in Pakistan by the MDRD equation or calculating the creatinine clearance using the Cockcroft Gault equation is a better predictor of reduced GFR than serum creatinine alone [43], and using serum creatinine alone may result in significant under-recognition of CKD as the level may still be within normal range even when the kidney function is impaired significantly.

A proper understanding of the KDOQI definition of CKD is required to be able to make the diagnosis of CKD [44]. Rates about awareness of KDOQI guidelines reported from other developing countries worldwide are low, with $38.8 \%$ of nonnephrology specialists in Nigeria being aware of the guidelines [45]. Low CKD awareness implies that these patients are not properly managed to delay the progression to ESRD [27]. Timely medical intervention which can slow progression of CKD and prevent ESRD has been advocate, since the cost of ESRD programmes is prohibitive, and the quality of life of patients on dialysis is poor [45]. One way of 
raising physicians' awareness on staging CKD is to recommend that laboratories should systematically calculate and even stage the eGFR based on the serum creatinine results [46]. Such a strategy has been shown to greatly increase the number of referrals to nephrologists $[47,48]$.

The majority of respondents in our study knew about "age-related decline" in GFR which is a natural process due to a diminution of nephrons in the body with aging. The majority recognized diabetes mellitus, hypertension, renal stone disease and chronic glomerulonephritis as being risk factors for CKD. This was similar to results noted in a study in Cameroon [46], as well as in a web-based survey in the US [49]. Several studies have shown an increased risk for CKD among individuals with diabetes, hypertension, autoimmune diseases, urinary tract infections, stone diseases, and older age, among others [50]. Physicians involved in the care of CKD patients should pay attention to a wide range of disorders that may develop as a result of loss of renal function; it is important to recognize all the complications of CKD in order to reduce diseaserelated morbidity and mortality [38]. The potential complications of CKD were identified by a majority of the respondents, but fewer attending doctors (66.7\%) identified cardiovascular disease as a complication of CKD. The most commonly identified complication was anemia, similar to other studies $[38,45,46,49]$.

In our study, $84 \%$ of house-officers, $97.3 \%$ of PG trainees and $87.5 \%$ of attending doctors believed that late referral [when patient becomes symptomatic of uremia] to a nephrologist causes high mortality and morbidity. However, only $56 \%$ of houseofficers, $78 \%$ of $\mathrm{PGs}$ and $75 \%$ of attending doctors would refer patients with a creatinine of 3 or above to a nephrologist. Several studies have shown that late referral to nephrologists is usually associated with adverse outcomes [51-53]. The KDOQI guidelines recommend that patients with CKD should be referred to a nephrologist when eGFR is less than 60 $\mathrm{ml} / \mathrm{min}$ [50]. The potential benefits of early referral include slowing CKD progression with timed interventions, informed selection of dialysis modality and non-emergent initiation of dialysis, less frequent and shorter hospital stays, lower cost, improved survival and likelihood of a pre-emptive transplant [38]. A study from the US showed that approximately 25$50 \%$ of patients starting chronic renal replacement therapy require dialysis within one month of their first nephrology visit [54]. In a Pakistan study, 84\% of physicians knew that late nephrology referral translates into higher morbidity and mortality, but $48 \%$ were unaware as to when to refer the patient to a nephrologist based on eGFR [31]. In the Nigeria study, very few respondents knew about the criteria for referring CKD patients to nephrology [45]. In order to initiate timely referral of CKD patients, primary providers need to be aware of risk factors for CKD and comorbidities associated with CKD, as well as clinical practice guidelines describing optimal CKD care, such as the KDOQI guidelines [50], the recommendations from the American Diabetes Association (ADA) [21], or the clinical practice guidelines developed by the Renal Physicians Association (RPA) [55].

There is substantial evidence suggesting the efficacy of Angiotensin Converting Enzyme (ACE) Inhibitors and Angiotensin Receptor Blockers (ARBs) in decreasing albuminuria, and delaying the progression from microalbuminuria to macroalbuminuria in patients with proteinuria and CKD $[56,57]$. The KDOQI guidelines recommend a target blood pressure [BP] of less than $130 / 80 \mathrm{mmHg}$ in patients with $C K D$, and the preferred choice of antihypertensive for both diabetic and non-diabetic kidney disease are ACE Inhibitors and ARBs [22]. In our study only $54 \%$ of attendings and $32 \%$ of house-officers could correctly identify the goal BP for CKD, and the number among PG trainees was higher [63\%]. However, the majority did choose ACE Inhibitors and ARBs as the class of antihypertensives they used in patients with CKD. For the $25 \%$ of doctors who did not 
choose this class of drugs, it may be necessary to disseminate information about the usefulness of a given intervention, and also give hand-on information about monitoring, prevention, and treatment of potential complications [49]. Data supporting the use of ACE Inhibitors and ARBs show that these agents are not only beneficial in patients with an abnormal serum creatinine, but also safe, as long as patients are carefully monitored and counseled [58, 59].

Regarding diabetes, the American Diabetes Association and the KDOQI work-group recommend that patients with diabetes should be screened annually for diabetic kidney disease [60]. It is especially important that clinicians are well-versed in the management of diabetes and its attendant complications, as diabetes is the leading cause of kidney failure world-wide, and its prevalence is high in the South Asian populations, and is expected to increase 2-fold till 2030 [57]. Initial screening for diabetes with a urine microalbumin should commence 5 years after the diagnosis of type 1 diabetes, and at the time of diagnosis of type 2 diabetes. In our study, about half of the HOs and PGs, and $66.7 \%$ of attendings knew that screening for diabetic nephropathy begins at diagnosis, and $56 \%$ of $\mathrm{HOs}, 67 \%$ of PGs and $66.7 \%$ of HOs routinely measured urinary microalbumin to screen for diabetic nephropathy. In another study on GPs in Pakistan, the majority were aware of when to start screening for diabetic nephropathy [38], and in the US study on trainees, 70\% elected to screen for microalbuminuria [49]. As the vast majority of diabetic CKD patients are under care of GPs and internal medicine doctors, it needs to be ensured that emphasis is placed on the teaching and hands-on implementation of clinical practice guidelines in order to improve the care of diabetic CKD patients.

Regarding practice parameters for CKD, the vast majority did admit to routinely measuring urinary protein and monitoring anemia parameters in CKD patients, but the number fell among the attending doctors to $70.8 \%$ regarding monitoring bone parameters for CKD patients. In the study by Lenz et al., the majority of doctors did not order anemia and screening tests for secondary hyperparathyroidism [49]. However, the questions did not evaluate the names of the clinical parameters in detail, so the answers may not reflect the accuracy of the screening tests being ordered. The screening for these complications of CKD should be initiated at Stage 3 of CKD, and unless educational efforts should be aimed specifically at non-nephrologists to fill these knowledge gaps.

The primary source of information on CKD for most doctors was textbooks, followed by online resources and CME seminars and medical journals falling back on the list. Recent data show that there is an acute lack of awareness of clinical practice guidelines for CKD patients among primary providers [32]. Only some doctors routinely provide dietary counseling to patients with CKD, with $56 \%$ of house-officers, $67.1 \%$ of PG trainees and $70.8 \%$ of attending, and this is another area that needs immediate attention. Doctors should be encouraged to read medical journals to stay abreast of latest research and trends in medical practice.

Regarding the overall results, junior doctors fared better probably due to the fact they have more knowledge of current guidelines, and they are more likely to comply with the current guidelines, whereas the senior doctors are more likely to be established in their set patterns of practice. The KDOQI guidelines have undergone major changes in the last decade or so, and unless associate professors and professors keep their knowledge up to date, their practice will also not be optimal. Educational efforts aimed at improving CKD care will have to be started for trainees and senior attending alike. In order to succeed, guidelines will have to be presented in a manner that fosters reflection, critically appraises clinical evidence, is practice-based, and is easy to understand for practitioners and patients alike [61]. Local and regional 
workshops and seminars, teaching aids like posters and leaflets, and the local and national media can all be used to highlight the issues related to the management of CKD. The international guidelines should be disseminated to doctors [trainees and those in practice], and local guidelines developed for CKD patients in Pakistan.

This study has some limitations, the population of doctors was limited to three campuses of a private teaching hospital, and the results may be generalizable to the larger set-up of public hospitals across the country. The study was conducted in a tertiary care hospital where patients pay a fee for consultation, which may affect attitudes towards early referral of patients. We cannot be certain that the answers truly reflect the knowledge of the person completing the survey, given that the survey instrument was not formally validated in this respect. However, we did receive a large number of responses from across the three campuses of our hospital, we believe that the data presented here are representative and cover important information about practice patterns of future providers.

\section{Conclusion}

In conclusion, our survey results suggest that doctors overall have significant knowledge gaps in CKD management, and these findings suggest that educational is needed to raise awareness of nephrology clinical practice guidelines and recommendations for CKD patients among our medical practitioners. This will have a significant impact on patient outcomes in a developing country with financial constraints, where the cost of care of end stage kidney patients is prohibitively expensive.

\section{Authors' Contributions}

Mahvesh Mahmud designed the survey, wrote the protocol and the manuscript. Nida Hussain assisted in the design of the survey and the literature sear- ches. Amal Kamal analyzed the data. Zarak Samoo, Wahaaj Khan collected the data for the study.

\section{Acknowledgement}

We thank Amna Hamid for part of the data collection.

\section{Competing Interests}

The authors declare no competing interests.

\section{References}

1. McCullough, B., et al. [2010] Sustainable community-based CKD screening methods employed by the National Kidney Foundation's Kidney Early Evaluation Program [KEEP]. American Journal of Kidney Diseases, 57, S4-S8

2. Khalil, A., Frazier, K., Lennie, T. \& Saway, P. [2011]. Depressive symptoms and dietary adherence in patients with end-stage renal disease. Journal of Renal Care, 37, 30-39

3. Lozano R., et al. [2013].Global and regional mortality from 235 causes of death for 20 age groups in 1990 and 2010: a systematic analysis for the Global Burden of Disease Study 2010. Lancet, 380, 2095-2128

4. Saleem Jessani, Rasool Bux and Tazeen H Jafar; Prevalence, determinants, and management of chronic kidney disease in Karachi, Pakistan - a community based cross-sectional study. BMC Nephrology 2014, 15:90

5. Vassalotti JA, Stevens LA, Levey AS. Testing for chronic kidney disease: a position statement from the National Kidney Foundation. Am J Kidney Dis 2007; 50[2]:169-180. [PubMed: 17660017]

6. El Nahas, A. \& MMedSci, A. [2005] Chronic Kidney Disease: the global challenge. Lancet, 365, 331-340

7. A. Khalil \& M. Abdalrahim. Knowledge, attitudes, and practices towards prevention and early detection of chronic kidney disease. International Nursing Review 2014

8. Ibrahim, M. \& Damasceno, A. [2012] Hypertension in developing countries. Lancet, 382, 611-619

9. Wetterhall SF, Olson DR, DeStefano F, et al. Trends in diabetes and diabetic complications, 1980-1987. Diabetes Care. 1992; 15: $960-7$

10. Coresh J, Astor B, Sarnak MJ. Evidence for increased cardiovascular disease risk in patients with chronic kidney disease. Curr Opin Nephrol Hypertens 2004; 13: 73-81.

11. Sarnak MJ, Levey AS, Schoolwerth AC, et al. Kidney disease as a risk factor for development of cardiovascular disease: a statement from the American Heart Association Councils on Kidney in Cardiovascular Disease, High Blood Pressure Research, Clinical Cardiology, and Epidemiology and Prevention. Hypertension 2003; 42: 1050-65.

12. Go AS, Chertow GM, Fan D, McCulloch CE, Hsu CY. Chronic kidney disease and the risks of death, cardiovascular events, and hospitalization. N Engl J Med 2004; 351: 1296-305. 
13. Anavekar NS, McMurray JJ, Velazquez EJ, et al. Relation between renal dysfunction and cardiovascular outcomes after myocardial infarction. N Engl J Med 2004; 351: 1285-95.

14. Jafar TH, Levey AS, Jafary FH, White F, Gul A, Rahbar MH, et al. Ethnic subgroup differences in hypertension in Pakistan. J Hypertension 2003; 21:905-12

15. Shera AS, Rafique G, Khawaja IA, Ara J, Baqai S, King H. Pakistan national diabetes survey: prevalence of glucose intolerance and associated factors in Shikarpur, Sindh Province, Diabetes Med 1995; 12 - 1116-21

16. Go AS, Chertow GM, Fan D, McCulloch CE, Hsu CY. Chronic kidney disease and the risks of death, cardiovascular events, and hospitalization. N Engl J Med 2004; 351[13]:1296-1305. [PubMed:15385656]

17. Plantinga LC, Boulware LE, Coresh J, Stevens LA, Miller ER 3rd, Saran R, Messer KL, Levey AS, Powe NR. Patient awareness of chronic kidney disease: trends and predictors. Arch Intern Med 2008; 168[20]:2268-2275. [PubMed: 19001205]

18. Nickolas TL, Frisch GD, Opotowsky AR, Arons R, Radhakrishnan J. Awareness of kidney disease in the US population: findings from the National Health and Nutrition Examination Survey [NHANES]1999 to 2000. Am J Kidney Dis 2004; 44[2]:185-197. [PubMed: 15264176]

19. Coresh J, Byrd-Holt D, Astor BC, Briggs JP, Eggers PW, Lacher DA, Hostetter TH. Chronic kidney disease awareness, prevalence, and trends among U.S. adults, 1999 to 2000. J Am Soc Nephrol 2005; 16[1]:180-188. [PubMed: 15563563]

20. Paul A. James, MD1; Suzanne Oparil, MD2; Barry L. Carter, PharmD1; William C. Cushman, MD3; Cheryl DennisonHimmelfarb, RN, ANP, PhD4; Joel Handler, MD5; Daniel T. Lackland, DrPH6; Michael L. LeFevre, MD, MSPH7; Thomas D. MacKenzie, MD, MSPH8; Olugbenga Ogedegbe, MD, MPH, MS9; Sidney C. Smith Jr, MD10; Laura P. Svetkey, MD, MHS11; Sandra J. Taler, MD12; Raymond R. Townsend, MD13; Jackson T. Wright Jr, MD, PhD14; Andrew S. Narva, MD15; Eduardo Ortiz, MD, MPH. 2014 Evidence-Based Guideline for the Management of High Blood Pressure in Adults Report From the Panel Members Appointed to the Eighth Joint National Committee [JNC 8] JAMA. 2014; 311[5]:507-520. doi:10.1001/jama.2013.284427.

21. Standards of Medical Care in Diabetes Care. Position Statement of the American Diabetes Association. Diabetes Care, Volume 32, Supplement 1, Jan 2009

22. Levey AS, Atkins R, Coresh J, Cohen EP, Collins AJ, Eckardt KU, Nahas ME, Jaber BL, Jadoul M, Levin A, Powe NR, Rossert J, Wheeler DC, Lameire N, Eknoyan G. Chronic kidney disease as a global public health problem: approaches and initiatives - a position statement from Kidney Disease Improving Global Outcomes. Kidney Int 2007; 72[3]:247-259. [PubMed: 17568785]

23. Levey AS, Andreoli SP, DuBose T, Provenzano R, Collins AJ. Chronic kidney disease: common, harmful and treatable--World Kidney Day 2007. Am J Nephrol 2007; 27[1]:108-112. [PubMed: 17308371]
24. Chin HJ, Ahn JM, Na KY, Chae DW, Lee TW, Heo NJ, Kim S. The effect of the World Kidney Day campaign on the awareness of chronic kidney disease and the status of risk factors for cardiovascular disease and renal progression. Nephrol Dial Transplant. 2009 in press.

25. Bakris G, Collins AJ. Executive summary: Kidney Early Evaluation Program [KEEP] 2007 Annual Data Report. Am J Kidney Dis 2008; 51[4]:S1-S2. [PubMed: 18359402]

26. Vassalotti JA, Li S, Chen SC, Collins AJ. Screening populations at increased risk of CKD: The Kidney Early Evaluation Program [KEEP] and the public health problem. Am J Kidney Dis 2009; 53[3 Suppl3]: S107-S114. [Pub Med: 19231754]

27. Lin CL, Chuang FR, Wu CF, Yang CT. Early referral as an independent predictor of clinical outcome in end-stage renal disease on hemodialysis and continuous ambulatory peritoneal dialysis. Renal Failure 2004; 26 [0886-022; 5]:531-537. [Pub Med: 15526911]

28. Kinchen KS, Sadler J, Fink N, Brookmeyer R, Klag MJ, Levey AS, Powe NR. The timing of specialist evaluation in chronic kidney disease and mortality. Ann Intern Med 2002; 137[6]:479-486. [PubMed:12230348]

29. Roderick P, Jones C, Drey N, Blakeley S, Webster P, Goddard J, Garland S, Bourton L, Mason J, Tomson C. Late referral for end-stage renal disease: a region-wide survey in the south west of England. Nephrol Dial Transplant 2002; 17[7]:1252-1259. [PubMed: 12105249]

30. Jungers P, Massy ZA, Nguyen-Khoa T, Choukroun G, Robino C, Fakhouri F, Touam M, Nguyen AT, Grunfeld JP. Longer duration of predialysis nephrological care is associated with improved long-term survival of dialysis patients. Nephrol Dial Transplant 2001; 16[12]:2357-2364. [Pub Med:11733627]

31. Tamizuddin S, Ahmed W. Knowledge, attitude and practices regarding chronic kidney disease and estimated GFR in a tertiary care hospital in Pakistan. JPMA May 2010

32. Boulware LE, Troll MU, Jaar BG, Myers DI, Powe NR. Identification and referral of patients with progressive CKD: a national study. Am J Kidney Dis 2006; 48: 192-204

33. Goransson LG, Bergrem $H$. Consequences of late referral of patients with end-stage renal disease. J Int Med 2001; 250: 1549

34. Kinchen KS, Sadler J, Fink N, Brookmeyer R, Klag MJ, Levey AS, et al. The timing of specialist evaluation in chronic kidney disease and mortality. Ann Inter Med 2002; 137: 479-86

35. Chan MR, Dall AT, Fletcher KE, Lu N, Trivedi H. Outcomes in patients with chronic kidney disease referred late to nephrologists: a meta-analysis. Am J Med 2007; 120: 1063-70

36. Sakhuja V, Sud K. End-stage renal disease in India and Pakistan: Burden of disease and management issues. Kidney International Suppl. 2003; 83: S 115-8. [PubMeD)

37. Muhammad Anees, Asim Mumtaz, Saleem Uz Zaman Adhmi, Muhammad Ibrahim. Knowledge, attitude and practices (KAP) of chronic kidney disease among medical officers of teaching hospitals of Lahore. Annals Vol 20, Issue 1, Jan -Mar 2014 
38. S. Yaqub, W. Kashif, M. Q. Raza, H. Aaqil, A. Shahab, M. A. Chaudhary, and S. A. Hussain. General practitioners' knowledge and approach to chronic kidney disease in Karachi, Pakistan. Indian J Nephrol. 2013 May-Jun; 23[3]: 184-190

39. Jafar TH. The growing burden of chronic kidney disease in Pakistan. N Engl J Med. 2006; 354:995-7.

40. The KAP survey model [knowledge, attitude and practices], SPRING, https://www.spring-nutrition.org/publications/toolsummaries/kap-survey-model-knowledge-attitudes-andpractices

41. Lesley A. Inker, Brad C. Astor, Chester H. Fox, Tamara Isakova, James P. Lash, Carmen A. Peralta, Manjula Kurella Tamura, Harold I. Feldman, KDOQI US Commentary on the 2012 KDIGO Clinical Practice Guideline for the Evaluation and Management of CKD. AJKD May 2014. Volume 63, Issue 5, Pages 713-735

42. Fox $\mathrm{CH}$, Brooks A, Zayas LE, McClellan W, Murray B. Primary care physicians' knowledge and practice patterns in the treatment of chronic kidney disease: An upstate New York Practice-based Research Network [UNYNET] stud. J Am Board Family Medicine. 2006; 19: 54-61. [PubMeD)

43. Jafar $\mathrm{TH}$, Scmid $\mathrm{CH}$, Levey AS. Serum creatinine as a marker of kidney function in South Asians: A study of reduced GFR in adults in Pakistan. J Am Soc Nephrol 2005; 16: 1413-9

44. National Kidney Foundation. K/DOQI clinical practice guidelines for chronic kidney disease: evaluation, classification and stratification. Am J Kidney Dis. 2002; 39: S1-266.

45. Agaba E, Agaba P, Dankyau M, Akanbi M, Daniyam C, Okeke E, et al. Specialist physician knowledge of chronic kidney disease: a comparison of internists and family physicians in West Africa. Afr J Prm Health Care Fam Med. 2012; 4[1]:7.

46. Simeon-Pierre Choukem, Pennghan K. Nchifor, Marie-Patrice Halle, Daniel N. Nebongo, Yannick Mboue-Djieka, François F. Kaze and Gotlieb L. Monekosso. Knowledge of physicians on chronic kidney disease and their attitudes towards referral, in two cities of Cameroon: a cross-sectional study. BMC Res Notes [2016] 9:29 DOI 10.1186/s13104-016-1845-5

47. Noble E, Johnson DW, Gray N, Hollett P, Hawley CM, Campbell $S B$, et al. The impact of automated eGFR reporting and education on nephrology service referrals. Nephrol Dial Transplant. 2008; 23[12]:3845-50. 17

48. Kagoma YK, Weir MA, lansavichus AV, Hemmelgarn BR, Akbari A, Patel UD, et al. Impact of estimated GFR reporting on patients, clini cians, and health-care systems: a systematic review. Am J Kidney Dis. 2011; 57[4]:592-601

49. Lenz O, Fornoni A. Chronic kidney disease care delivered by US family medicine and internal medicine trainees: Results from an online survey. BMC Med. 2006; 4:30.

50. KDOQI clinical practice guidelines for chronic kidney disease: Evaluation, classification and stratification. Am J Kidney Disease. 2002; 39: S1-266. [PubMeD)

51. Halle MP, Kengne AP, Ashuntantang G. Referral of patients with kidney impairment for specialist care in a developing country of sub-Saharan Africa. Ren Fail. 2009; 31[5]:341-8.

52. Winkelmayer WC, Owen WF Jr, Levin R, Avorn J. A propensity analysis of late versus early nephrologist referral and mortality on dialysis. J Am Soc Nephrol. 2003; 14[2]:486-92
53. Peña J, Logroño J, Pernaute R, Laviades C, Virto R, de Vincente Vera C. Late nephrology referral influences on morbidity and mortality of hemodialy sis patients. A provincial study. Nefrologia. 2006; 26[1]:84-97.

54. Kazmi WH, Obrador GT, Khan SS, Pereira BJ, Kausz AT. Late nephrology referral and mortality among patients with endstage renal disease: a propensity score analysis. Nephrol Dial Transplant. 2004; 19:1808-14

55. Bolton WK: Renal physicians association clinical practice guideline: appropriate patient preparation for renal replacement therapy: guideline number 3. J Am Soc Nephrol 2003, 14:14061410

56. Brenner BM, Cooper ME, de Zeeuw D, Keane WF, Mitch WE, Parving $\mathrm{HH}$, et al. Effects of losartan on renal and cardiovascular outcomes in patients with type 2 diabetes and nephropathy. $\mathrm{N}$ Engl J Med. 2001; 345; 861-9

57. Jafar TH, Schmid CH, Landa M, Giatras I, Toto R, Remuzzi G, et al. Aniotensin-converting enzyme inhibitors and progression of nondiabetic renal disease. A meta-analysis of patient-level data. Ann Intern Med. 2001; 135:73-87.

58. Bloom JM: Benazepril for advanced chronic renal insufficiency. N Engl J Med 2006, 354:1530-1531

59. Mann JF, Gerstein HC, Pogue J, Bosch J, Yusuf S: Renal Insufficiency as a predictor of cardiovascular outcomes and the impact of ramipril: the HOPE randomized trail. Ann Intern Med 2001,134:629-636

60. KDOQI. KDOQI clinical practice guidelines and clinical practice recommendations for diabetes and chronic kidney disease. Am J Kidney Dis. 2007; 49:S12-154

61. Baker R: Is it time to review the idea of compliance with guidelines? Br J Gen Pract 2001, 51:7

\section{Publish in International Archives of Medicine}

International Archives of Medicine is an open access journal publishing articles encompassing all aspects of medical science and clinical practice. IAM is considered a megajournal with independent sections on all areas of medicine. IAM is a really international journal with authors and board members from all around the world. The journal is widely indexed and classified Q1 in category Medicine. 